\title{
El aislamiento de los Estados Unidos
}

Noam Chomsky*

El 23 de diciembre de 2016, el Consejo de Seguridad de la ONU aprobó la Resolución 2334 por unanimidad, con la abstención de los Estados Unidos. La Resolución reafirmaba "que la política y las prácticas de Israel en el establecimiento de asentamientos en los territorios palestinos y otros territorios árabes ocupados desde 1967 carecen de validez jurídica y constituyen un grave obstáculo para el logro de una paz amplia, justa y duradera en oriente medio [y] exhorta una vez más a Israel, como potencia ocupante, a que cumpla escrupulosamente el Cuarto Convenio de Ginebra de 1949, que revoque sus medidas anteriores y desista de tomar cualquier acción que tenga como resultado la modificación del estatus legal y la naturaleza geográfica y que afecte materialmente a la composición demográfica de los territorios árabes ocupados desde 1967, incluida Jerusalén y, en particular, que no transfiera partes de su propia población civil a los territorios árabes ocupados".

\section{REAFIRMADO. UN ASUNTO DE CIERTA IMPORTANCIA}

Es importante reconocer que la Resolución 2334 no es nada nuevo. La cita anterior es de la Resolución 446 del CSNU, del 12 de marzo de 1979, reiterada en esencia en la 2334. La Resolución 446 fue aprobada por 12 a 0 con la abstención de los Estados Unidos, a la que se sumaron el Reino Unido y Noruega. A esta Resolución le siguieron varias que reafirmaban la 446. Un año más tarde, una resolución de especial interés fue incluso más contundente que la 446-2334, en la que se instaba a Israel a "desmantelar los asentamientos existentes" (Resolución 465 del CSNU, marzo de 1980), esta vez aprobada por unanimidad, sin abstenciones.

* Noam Chomsky es profesor institucional (emérito) en el Departamento de Lingüística y Filosofía del Instituto de Tecnología de Massachusetts y profesor laureado de Lingüística Silla Agnesse Nelms Haury en el programa en Ambiente y Justicia Social de la Universidad de Arizona. Su trabajo se reconoce ampliamente por haber revolucionado el campo de la lingüística moderna. Es autor de numerosos best-selling trabajos políticos, que han sido traducidos en decenas de países. Más información en https://chomsky.info.

Recibido: 14 de diciembre de 2020 / Aceptado: 15 de diciembre de 2020

Para citar este artículo:

Chomsky, N. (2021). El aislamiento de los Estados Unidos. OASIS, 34, pp. 199-205. Artículo original: Noam Chomsky (2016) US Isolation, https://chomsky.info/20161230/, Traducción de Michael Robert Forrest; se publica con la autorización correspondiente.

DoI: https://doi.org/10.18601/16577558.n34.11 
El Gobierno de Israel no tuvo que esperar al Consejo de Seguridad de la onu (y más recientemente, al Tribunal Mundial) para saber que sus asentamientos constituyen una grave violación del derecho internacional. En septiembre de 1967, solo unas semanas después de la conquista de los territorios ocupados por parte de Israel, en un documento de Alta Confidencialidad, el Gobierno fue informado por el asesor jurídico del Ministerio de Relaciones Exteriores, el distinguido abogado internacional Theodor Meron, de que "los asentamientos civiles en los territorios administrados [término utilizado por Israel para referirse a los territorios ocupados] contravienen disposiciones explícitas de la Cuarta Convención de Ginebra”. Meron explicó además que la prohibición del traslado de colonos a los territorios ocupados “es categórica y no está condicionada por los motivos del traslado o sus objetivos. $\mathrm{Su}$ propósito es impedir el asentamiento en territorio ocupado de ciudadanos del Estado ocupante". Por lo tanto, Meron aconsejó que "si se decide seguir adelante con el asentamiento de judíos en los territorios administrados, me parece vital, por lo tanto, que el asentamiento sea llevado a cabo por entidades militares y no civiles. También es importante, en mi opinión, que dicho asentamiento se realice en el marco de campamentos y sea, a primera vista, de carácter temporal y no permanente".

Se siguió el consejo de Meron. Los asentamientos se han disfrazado a menudo con el subterfugio sugerido, las "entidades militares temporales" resultan ser después asentamientos civiles. El dispositivo de asentamiento militar tiene también la ventaja de proporcionar un medio para expulsar a los palestinos de sus tierras con el pretexto de que se está estableciendo una zona militar. El engaño fue escrupulosamente planificado, comenzando tan pronto como el autorizado informe de Meron fue entregado al gobierno. Como documenta el académico israelí Avi Raz, en septiembre de 1967, el día en que se creó un segundo asentamiento civil en Cisjordania, el gobierno decidió que "como 'tapadera' a efectos de la campaña diplomática [de Israel]" los nuevos asentamientos debían presentarse como asentamientos del ejército y los colonos debían recibir las instrucciones necesarias en caso de que se les preguntara por la naturaleza de su asentamiento. El Ministerio de Relaciones Exteriores dio instrucciones a las misiones diplomáticas de Israel para que presentaran los asentamientos en los territorios ocupados como "puntos fuertes" militares y subrayaran su supuesta importancia para la seguridad.

\section{PRÁCTICAS SIMILARES CONTINÚAN HASTA HOY EN DÍA, MIENTRAS LOS “PARTIDARIOS DE ISRAEL" FINGEN NO VER}

Las órdenes del Consejo de Seguridad de 197980 de desmantelar los asentamientos existentes y de no establecer otros nuevos fueron seguidas de inmediato por una rápida expansión de los asentamientos por parte de los dos principales bloques políticos israelíes, el Laborista y el Likud, siempre con el abundante apoyo material de los Estados Unidos.

Las principales diferencias hoy en día son que los EE. UU. está ahora solo contra todo el mundo, y que es un mundo diferente. Las flagrantes violaciones de Israel de las órdenes del Consejo de Seguridad, y del derecho inter- 
nacional, son ahora mucho más extremas que hace 35 años, y suscitan una condena mucho mayor en gran parte del mundo. Por lo tanto, el contenido de la Resolución 446-2334 se toma más en serio. De ahí las reveladoras reacciones a la 2334, y a la explicación del Secretario de Estado John Kerry sobre el voto de los Estados Unidos. En el mundo árabe, las reacciones parecen haber sido silenciosas: Ya hemos pasado por esto. En Europa, en general, fueron de apoyo. En Estados Unidos e Israel, en cambio, la cobertura y los comentarios fueron amplios, y hubo una histeria considerable. Estos son otros indicios del creciente aislamiento de los Estados Unidos en la escena mundial. Es decir, bajo Obama. Con Trump, el aislamiento de los EE. UU. probablemente aumentará aún más, y de hecho ya lo hizo, incluso antes de que asumiera el cargo.

El paso más significativo de Trump para avanzar en el aislamiento de los Estados Unidos fue el 8 de noviembre, cuando obtuvo dos victorias. La victoria menor fue en los Estados Unidos, donde ganó el voto electoral (mientras que perdió el voto popular por cerca de 3 millones; su victoria se basó en características regresivas del sistema político estadounidense). La victoria mayor fue en Marrakech (Marruecos), donde unas 200 naciones se reunieron para intentar dotar de contenido real a los acuerdos de París de diciembre de 2015 sobre el cambio climático, que quedaron en promesas y no en el pretendido tratado porque el Congreso republicano no aceptó compromisos vinculantes.

A medida que se iban conociendo los votos electorales del 8 de noviembre, la conferencia de Marrakech pasó de su programa sus- tantivo a la cuestión de si podría haber alguna acción significativa para tratar con la ominosa amenaza de catástrofe medioambiental ahora que el país más poderoso de la historia del mundo se da por vencido. Esa fue, sin duda, la mayor victoria de Trump el 8 de noviembre, una de importancia verdaderamente trascendental. También estableció el aislamiento de los Estados Unidos en el problema más grave al que se ha enfrentado el ser humano en su corta historia en la Tierra. El mundo depositó sus esperanzas de liderazgo en China, ahora que el Líder del Mundo Libre declaró que no solo se retirará del esfuerzo, sino que, con la elección de Trump, se moverá con fuerza para acelerar la carrera hacia el desastre.

\section{UN ESPECTÁCULO SORPRENDENTE, QUE PASÓ PRÁCTICAMENTE SIN COMENTARIOS}

El hecho de que los Estados Unidos esté ahora solo en el rechazo del consenso internacional reafirmado en la Resolución 2334 del Consejo de Seguridad de la onu es otra señal del creciente aislamiento de Estados Unidos.

El motivo por el que Obama optó por la abstención en lugar del veto es una cuestión abierta: no tenemos pruebas directas. Pero hay algunas conjeturas plausibles. Hubo algunas ondas de sorpresa (y de ridículo) tras el veto de Obama en febrero de 2011 a una resolución del CSNU que pedía la aplicación de la política oficial de los Estados Unidos, y puede haber sentido que sería demasiado repetirlo si quiere salvar algo de su andrajoso legado entre los sectores de la población que tienen cierta preocupación por el derecho internacional y los derechos humanos. También conviene 
recordar que entre los demócratas liberales, si no en el Congreso, y sobre todo entre los jóvenes, la opinión sobre Israel-Palestina ha ido evolucionando hacia la crítica de las políticas israelíes en los últimos años, hasta el punto de que "el 60\% de los demócratas apoyan la imposición de sanciones o acciones más serias", como reacción a los asentamientos israelíes, según una encuesta del Instituto Brookings de diciembre de 2016. A estas alturas, el núcleo de apoyo a las políticas israelíes en los Estados Unidos se ha desplazado hacia la extrema derecha, incluida la base evangélica del Partido Republicano. Tal vez estos fueron factores en la decisión de Obama.

La abstención de 2016 despertó el furor en Israel y también en el Congreso de EE. UU., tanto de los republicanos como de los principales demócratas, incluyendo propuestas para desfinanciar la ONU en represalia por el crimen mundial. El primer ministro israelí, Netanyahu, denunció a Obama por sus acciones "solapadas y antiisraelíes". Su oficina acusó a Obama de "confabular" entre bastidores con esta "confabulación" del CSNU, produciendo partículas de "evidencia" que difícilmente alcanzan el nivel de humor enfermo. Un alto funcionario israelí añadió que la abstención "revelaba la verdadera cara de la administración Obama”, y añadió que "ahora podemos entender a qué nos hemos enfrentado durante los últimos ocho años".

La realidad es bastante diferente. De hecho, Obama ha batido todos los récords de apoyo a Israel, tanto diplomático como financiero. La realidad es descrita con precisión por el especialista en oriente medio, del Financial Times, David Gardner:
El trato personal del señor Obama con el señor Netanyahu puede haber sido a menudo venenoso, pero ha sido el más pro-israelí de los presidentes: el más pródigo con la ayuda militar y fiable a la hora de ejercer el veto de EE. uU. en el Consejo de Seguridad... La elección de Donald Trump ha aportado hasta ahora poco más que tuits turboalimentados para influir en este y otros nudos geopolíticos.

Pero los augurios son ominosos. A un gobierno irredentista en Israel, inclinado hacia la ultraderecha, se une ahora una administración nacional populista en Washington que respira islamofobia.

Los comentarios públicos sobre la decisión de Obama y la justificación de Kerry estuvieron divididos. Los partidarios estuvieron en general de acuerdo con Thomas Friedman en que "Israel está ahora claramente en camino de absorber a los 2,8 millones de palestinos de Cisjordania...., lo que supone un reto demográfico y democrático”. En un análisis del New York Times sobre el estado de la solución de dos Estados defendida por Obama-Kerry (y la 2334 del Consejo de Seguridad de la onu) y amenazada de extinción por las políticas israelíes, Max Fisher se pregunta “¿Hay otras soluciones?” A continuación pasa a analizar las posibles alternativas, todas ellas "versiones múltiples de la llamada solución de un solo Estado" que plantea el "desafío demográfico y democrático" de demasiados árabes -quizá pronto una mayoría- en un "Estado judío y democrático".

De manera convencional, los comentaristas parten de la base de que hay dos alternativas: la solución de dos Estados que defiende el mundo, o alguna versión de la "solución de un Estado”. Se ignora sistemáticamente 
una tercera alternativa, la que Israel ha estado aplicando de forma bastante sistemática desde poco después de la guerra de 1967 y que ahora está tomando forma muy claramente ante nuestros ojos: un Gran Israel, tarde o temprano incorporado al propio Israel, incluyendo una Jerusalén enormemente ampliada (ya anexionada en violación de las órdenes del Consejo de Seguridad) y cualquier otro territorio que Israel considere valioso, al tiempo que se excluyen las zonas de gran concentración de población palestina y se expulsa a los palestinos de las zonas previstas para su incorporación al Gran Israel. Al igual que en las neocolonias en general, las élites palestinas podrán disfrutar de los estándares occidentales en Ramallah, con "el 90\% de la población de Cisjordania viviendo en 165 "islas" separadas, aparentemente bajo el control de la [Autoridad Palestina]", pero con el control real de Israel, como informó Nathan Thrall, analista principal del International Crisis Group. Gaza seguirá bajo un asedio aplastante, separada de Cisjordania en violación de los Acuerdos de Oslo.

\section{LA TERCERA ALTERNATIVA ES OTRA PIEZA DE LA “REALIDAD” DESCRITA POR DAVID GARDNER}

En un comentario interesante y revelador, Netanyahu denunció que la "patota" del mundo es una prueba del "sesgo del viejo mundo contra Israel", una frase que recuerda la distinción Vieja Europa-Nueva Europa de Donald Rumsfeld en 2003.

Cabe recordar que los Estados de la Vieja Europa eran los malos, los principales Estados de Europa, que se atrevieron a respetar la opi- nión de la inmensa mayoría de sus poblaciones y, por tanto, se negaron a unirse a Estados Unidos en el crimen del siglo, la invasión de Iraq. Los Estados de la Nueva Europa fueron los buenos, que anularon una mayoría aún mayor y obedecieron al amo. El más honorable de los buenos fue el español José María Aznar, que rechazó la oposición prácticamente unánime a la guerra en España y fue recompensado al ser invitado a unirse a Bush y Blair en el anuncio de la invasión.

Esta muestra bastante esclarecedora de absoluto desprecio por la democracia, junto con otras de la misma época, pasó prácticamente desapercibida, como es lógico. La tarea en ese momento era alabar a Washington por su apasionada dedicación a la democracia, como ilustra la "promoción de la democracia" en Irak que, de repente, se convirtió en la línea del partido después de que la "única pregunta" (¿̨renunciará Saddam a sus armas de destrucción masiva?) se respondiera de forma equivocada.

Netanyahu está adoptando una postura muy parecida. El viejo mundo que está predispuesto contra Israel es todo el Consejo de Seguridad de la onU; más concretamente, cualquier persona del mundo que tenga algún compromiso persistente con el derecho internacional y los derechos humanos. Por suerte para la extrema derecha israelí, eso excluye al Congreso de los EE.uU. y -de forma muy contundente- al presidente electo y sus asociados.

El gobierno israelí es, por supuesto, consciente de estos acontecimientos. Por lo tanto, está tratando de cambiar su base de apoyo a los Estados autoritarios como Singapur, China y la India nacionalista hindú de Modi, que ahora se está convirtiendo en un aliado muy natural con 
su deriva hacia el ultranacionalismo, las políticas internas reaccionarias y el odio al islam. Las razones por las que Israel busca apoyo en esta dirección son expuestas por Mark Heller, principal investigador asociado de la Institución de Estudios de Seguridad Nacional de Tel Aviv. "A largo plazo", explica, "hay problemas para Israel en sus relaciones con Europa occidental y con los Estados Unidos", mientras que, por el contrario, los países asiáticos importantes "no parecen indicar mucho interés sobre cómo se lleva Israel con los palestinos, los árabes o cualquier otro”. En resumen, China, India, Singapur y otros aliados favorecidos están menos influenciados por el tipo de preocupaciones liberales y humanas que suponen una amenaza creciente para Israel.

Las tendencias que se están desarrollando en el orden mundial merecen cierta atención. Como se ha señalado, los Estados Unidos se está quedando aún más aislado de lo que ha estado en los últimos años, cuando las encuestas realizadas por los Estados Unidos -de las que no se informa en los Estados Unidos, pero que seguro se conocen en Washington- revelaron que la opinión mundial consideraba a los Estados Unidos como la principal amenaza para la paz mundial con diferencia, sin que nadie más se acercara. Bajo el mandato de Obama, los Estados Unidos está solo en la abstención sobre los asentamientos ilegales de Israel, en contra de la unanimidad del csNu. Con Trump y sus partidarios bipartidistas en el Congreso, los Estados Unidos estará aún más aislado en el mundo en apoyo de los crímenes israelíes. Desde el 8 de noviembre, los EE.UU. está aislado en el asunto mucho más crucial del calentamiento global, una amenaza para la supervivencia de la vida humana organizada en algo parecido a su forma actual. Si Trump cumple su promesa de salir del acuerdo con Irán, es probable que los otros participantes persistan, dejando a los Estados Unidos aún más aislado de Europa. Los EE.UU. también está mucho más aislado de su "patio trasero" latinoamericano que en el pasado, y estará aún más aislado si Trump da marcha atrás en las medidas de Obama para normalizar las relaciones con Cuba, emprendidas para evitar la probabilidad de que los EE.UU. quede prácticamente excluido de las organizaciones hemisféricas debido a su continuo asalto a Cuba, en aislamiento internacional.

Lo mismo está ocurriendo en Asia, ya que incluso los aliados cercanos de los Estados Unidos (aparte de Japón), incluso el Reino Unido, acuden al Banco Asiático de Desarrollo de Infraestructuras con sede en China y a la Asociación Económica Integral Regional, con sede en China, en este caso incluyendo a Japón. La Asociación Económica Integral con base en China, que en este caso incluye a Japón. La Organización de Cooperación de Shanghái, con sede en China, incorpora a los Estados de Asia Central, a Siberia, con sus ricos recursos, a la India, a Pakistán y, pronto, probablemente a Irán y quizá a Turquía. La ocs ha rechazado la petición de los Estados Unidos de obtener el estatus de observador y ha exigido que retire todas sus bases militares de la región.

Inmediatamente después de la elección de Trump, asistimos al interesante espectáculo de la cancillera alemana, Ángela Merkel, tomando la iniciativa de dar lecciones a Washington sobre los valores liberales y los derechos humanos. Mientras tanto, desde el 8 de noviembre, el mundo busca en China el liderazgo para 
salvar al mundo de la catástrofe ambiental, mientras que los Estados Unidos, en espléndido aislamiento una vez más, se dedica a socavar estos esfuerzos.

El aislamiento de los Estados Unidos no es completo, por supuesto. Como quedó muy claro en la reacción a la victoria electoral de Trump, los Estados Unidos cuenta con el apoyo entusiasta de la ultraderecha xenófoba en Europa, incluidos sus elementos neofascistas. Y el regreso de la derecha en algunas partes de América Latina ofrece a los EE. UU. oportunidades de alianzas también allí. Y los Estados Unidos mantiene su estrecha alianza con la dictadura del Golfo y de Egipto, y con Israel, que también se está separando de los sectores más liberales y democráticos de Europa y se está vinculando con regímenes autoritarios a los que no les preocupan las violaciones del derecho internacional y los duros ataques a los derechos humanos elementales por parte de Israel.

El panorama que se está desarrollando sugiere el surgimiento de un Nuevo Orden Mundial, que es bastante diferente de las representaciones habituales dentro del sistema doctrinal.

Chomsky.info, 30 de diciembre de 2016 